\title{
Tonsillectomy and adenotonsillectomy showed modest benefits in children moderately affected with recurrent throat infection
}

\author{
Paradise JL, Bluestone CD, Colborn DK, et al. Tonsillectomy and adenotonsillectomy for recurrent throat infection in \\ moderately affected children. Pediatrics 2002;110:7-15. \\ QUESTION: In children moderately affected with recurrent throat infection, what is the \\ effectiveness of tonsillectomy or adenotonsillectomy?
}

\section{Design}

Randomised \{allocation concealed*\} $\uparrow$, unblinded,* controlled trial with 3 years of follow up.

\section{Setting}

Children's hospital in Pittsburgh, Pennsylvania, USA.

\section{Patients}

328 children between 3 and 15 years of age (60\% girls) who were moderately affected with recurrent episodes of throat infection (tonsillitis, pharyngitis, or tonsillopharyngitis: \{depending on age, 4-6 episodes in previous $1 \mathrm{y}$; or $6-8$ in previous $2 \mathrm{y}\} \dagger$ ). Children were excluded if they required immediate removal of large tonsils or adenoids because of obstructive symptoms. Follow up was $83 \%$ at year 1 .

\section{Intervention}

Children were stratified into those without obstructing adenoids, or recurrent or persistent otitis media $(\mathrm{n}=177$; 3 way trial) and those having $\geq 1$ of the above conditions $(\mathrm{n}=151 ; 2$ way trial). Children in the 3 way trial were allocated to a tonsillectomy ( $\mathrm{n}=58$ ), adenotonsillectomy $(n=59)$, or control $(n=60)$ group. Children in the 2 way trial were allocated to an adenotonsillectomy $(n=73)$ or control $(\mathrm{n}=78)$ group.

\section{Main outcome measures}

Episodes of throat infection, measures of throat related illness, and surgical complications.

\section{Main results}

Analysis was by intention to treat. At year 1, among children in the 3 way trial, fewer mean episodes of throat infection were seen in the tonsillectomy group $(1.96,95 \%$ CI 1.58 to $2.40, \mathrm{p}=0.02$ ) or adenotonsillectomy group $(1.85$, CI 1.51 to $2.34, \mathrm{p}=0.001)$ than in the control group (2.78, CI 2.35 to 3.26$)$. Similarly at year 1 , among children in the 2 way trial, fewer mean episodes of throat infection were seen in the adenotonsillectomy group (1.90, CI 1.56 to 2.28) than in the control group (3.60, CI 3.16 to 4.08, $\mathrm{p}<0.001$ ). At year 1 , among children in the 2 way trial, adenotonsillectomy was associated with fewer occurrences of cervical lymphadenopathy found at nonthroat infection visits $(2.6 \% v 7.1 \%, \mathrm{p} \leq 0.01)$ and fewer sore throat associated school absences (mean $3.5 v 6.6 \mathrm{~d} / \mathrm{y}$, $\mathrm{p}<0.01)$ than the control group; no difference between adenotonsillectomy and control groups were seen for sore throat days (mean $23 v 24 \mathrm{~d} / \mathrm{y}$ ). Mean duration of postoperative sore throat was 6.3 days, and $8 \%$ of children who received surgical treatment had surgery related complications, which were most commonly intraoperative $(1.5 \%)$ or postoperative $(3.4 \%)$ haemorrhage.

\section{Conclusion}

In children moderately affected with recurrent throat infection, tonsillectomy, and adenotonsillectomy showed modest benefits, but this must be weighed against the discomfort and complications of surgery.

*See glossary.

†Information provided by author.

\section{COMMENTARY}

Sore throat is 1 of the most common conditions managed in primary care, and tonsillectomy and adenotonsillectomy are still common reasons for operating on children. This study is welcome because it adds to the literature in an area where there is a paucity of trials. ${ }^{1-2}$

In this study by Paradise et al, some benefit from surgery in terms of a reduction in episodes of sore throat in children with frequent recurrent infections was clearly shown. The questions for clinicians and parents are "Is the benefit worth the cost?" and "What is the key benefit?" Arguably, the most important episodes to prevent are those where the child is more unwell. Although a mean of 1 episode of sore throat per child per year was saved by surgery, most of these episodes were classified as "mild". Among the more "at risk" children (those with recurrent or persistent otitis media, obstructing adenoids, or adenotonsillectomy), 4 children require an operation in order for 1 moderate or severe episode of sore throat per year to be prevented. In children without such risk factors, no clear benefit from adenotonsillectomy or tonsillectomy at 1 year was seen. Data on longer term benefit is more difficult to interpret because of high dropout rates. Against this benefit are the harms: the sore throat after surgery is normally severe, and $8 \%$ of children develop intra or postoperative complications (mainly haemorrhage).

Where does this leave us? The challenge for clinicians, given the likely modest benefit of surgery even in children most severely affected, is to better manage recurrent throat infections symptomatically using existing medical treatments. ${ }^{3}$ The challenge for researchers is to develop new methods of preventing recurrent infection using medical interventions.

Paul Little, MBBS, MRCP, FRCGP, MSc, DLSHTM University of Southampton School of Medicine Southampton, UK

1 Marshall T. A review of tonsillectomy for recurrent throat infection. BrJ Gen Pract 1998;48:1331-5.

Burton MJ, Towler B, Glasziou P. Tonsillectomy versus non-surgical treatment for chronic/recurrent acute tonsillinon-surgical treatment for chronic/recurrent acute
tis. Cochrane Database Syst Reo 2000;(2):CD001802.

3 Thomas M, Del Mar C, Glasziou P. How effective are treatments other than antibiotics for acute sore throat? $\mathrm{BrJ}$ Gen Pract 2000;50:817-20.
Source of funding: National Institute of Child Health and Human Development.

For correspondence: Dr J L Paradise Children's Hospital of Pittsburgh, Pittsburgh, PA,USA.jpar@pitt.edu 